\title{
Influence of Investment Granulometry on the Castability and Surface Roughness of Castings Obtained With Ni/Cr Alloys
}

\author{
Maria Beatriz Brisotti, Lucas da Fonseca Roberti Garcia ${ }^{\text {, }}$,Simonides Consani ${ }^{\text {b }}$ \\ Fernanda de Carvalho Panzeri Pires-de-Souza* \\ ${ }^{a}$ Department of Dental Materials and Prosthodontics, \\ School of Dentistry of Ribeirão Preto, University of São Paulo, \\ Av. do Café, s/no , Monte Alegre, 14040-904 Ribeirão Preto - SP, Brazil \\ ${ }^{\mathrm{b}}$ Department of Dental Materials, School of Dentistry of Piracicaba, University of Campinas, \\ Av. Limeira, 901, Areião, 13414-903 Piracicaba - SP, Brazil
}

Received: December 8, 2008; Revised: March 20, 2009

\begin{abstract}
The aim of this study was to verify the influence of investment granulometry on the castability and surface roughness of $\mathrm{Ni} / \mathrm{Cr}$ castings. Four investments were selected for casting according to decreasing order of granulometry: Heat Shock > Micro Fine $1700>$ Gilvest HS > Castotal. Castability was verified by means of 40 specimens made with a polyester screen and determined from the number of segments completely filled by the cast alloy. To analyze the roughness, 40 disk-shaped wax patterns were made $(15 \times 3 \mathrm{~mm})$, and after inclusion in the investments, they were cast and analyzed, before and after polishing (Mitutoyo SJ-201). The measurements were statistically analyzed $(1-$ ANOVA - Tukey $-\mathrm{p}<0.05)$ and it was verified that Heat Shock provided the worst castability with significant difference $(\mathrm{p}<0.05)$ when compared with other investments. This material and Castotal presented similar roughness before and after polishing, with statistically significant difference $(\mathrm{p}<0.05)$ between them and Gilvest and Micro Fine. It was concluded that investments with smaller granulometry provided castings that were more complete, but not smoother.
\end{abstract}

Keywords: investments, metal alloys, castability, surface roughness

\section{Introduction}

One of the constant concerns in Dentistry is to make restorative treatment available to the less privileged strata of the population. One of the ways of achieving this objective would be to use basic metal alloys (non-noble) instead of gold alloys, which were extensively used until the 1950's, but from then on their application became limited due to their high $\operatorname{cost}^{1-4}$.

Among the various properties of the alloys used as alternatives to gold, castability deserves more attention because it is of great clinical interest, since low castability could result in marginal failures in the restoration, leading to mis-adjustment of the prosthetic part ${ }^{5,6}$.

Various factors can influence the castability of an alloy, among them, its composition, surface tension and density, the direction of the force of cast, the types of machines used in the casting process, in addition to the sources of heating the alloy ${ }^{7-9}$. The investment used in the casting process of an alloy can also influence its castability, and has received a great deal of attention from researchers ${ }^{10-13}$. The granulometry of the investment, for example, can affect the setting time, surface roughness, in addition to a series of other properties of the casting ${ }^{14-16}$

Therefore, the aim of this study was to verify the influence of the granulometry of four commercial brands of investment on the castability and surface roughness, before and after polishing, of castings obtained from a Ni/Cr alloy. The hypothesis tested was that investments with smaller particles provide more complete castings with greater surface regularity.

\section{Materials and Methods}

To conduct this study, 4 phosphate-bonded investments with different granulometries were selected, as described in Table 1. Granulometry was calculated considering the percentage of powder retained in the strainers, ranging from 100 to 500 .

\subsection{Test specimen fabrication}

To analyze the castability, metal test specimens were fabricated from a polyester screen for a square shaped sieve, with $11 \times 11$ filaments with a thickness of $0.22 \mathrm{~mm}$, forming a mesh with 100 spaces. Blue wax was used to fix the screen along the two sides of a prefabricated post made of plastic resin, with a diameter of $2.5 \mathrm{~mm}$ and a feed canal-forming post made of resin, also prefabricated of plastic resin, but with a diameter of $3.5 \mathrm{~mm}$. The set was fixed to a crucible forming base at a distance of $0.5 \mathrm{~cm}$ from the test specimen.

To analyze the surface roughness, test specimens were fabricated by the lost wax technique. Initially, wax test specimens were obtained using a metal matrix with a smooth interior, formed by two parts that fitted together: an external portion and another internal, in the form of a plunger, $15 \mathrm{~mm}$ in diameter. Together with the matrix, a $3 \mathrm{~mm}$ thick spacer was fitted into the plunger between the top and bottom portions, so that the external part of the matrix was in a position $3 \mathrm{~mm}$ above the internal portion, providing a test specimen with an adequate thickness. The wax patterns and the plastic feed canal forming post with a diameter of $3.5 \mathrm{~mm}$ were united and fixed onto a crucible forming base. 


\subsection{Inclusion of samples}

Before being included in the investment, a surface tension reducing solution (Anti Bolhas-Pasom, São Paulo, SP, Brazil) was applied to the wax patterns with a No. 3 paint brush, in order to allow greater contact with the investment. The investments were initially manually worked with a spatula for 1 minute, and afterwards manipulated under vacuum (Inclusor A300, Polidental ${ }^{\circledR}$, São Paulo, SP, Brazil) for another 1 minute. The investments were applied to the wax patterns with a paint brush, and after the entire surface of the test specimen had been filled, the remainder of the material was poured onto the silicone rings under vibration until they were completely filled. After 24 hours, the crucible forming bases and the silicone rings with the included patterns were removed and placed in an electric furnace (EDG, São Carlos, SP, Brazil).

The investment cylinder was initially heated with the pyrometer set at ambient temperature. Heating was maintained at a constant speed of $15^{\circ} \mathrm{C}$ increase per minute, completing the first cycle when the temperature of $300{ }^{\circ} \mathrm{C}$ was reached and remained there for approximately 90 minutes. The second cycle finished when the temperature of $950{ }^{\circ} \mathrm{C}$ was attained, and remained there for approximately 30 minutes until the time of injecting the liquefied metal.

An oxygen/acetylene gas blowtorch was used as a heat source to melt the metal alloy (Vera Bond II $^{\circledR}$, Aalba Dent, Cordelia, USA). On melting, the liquefied alloy was injected into the investment molds by centrifugal force (Centrífuga Elétrica-EDG, São Carlos, SP, Brazil - $4500 \mathrm{rpm}$ ), in accordance with the dental casting technique by the lost wax process ${ }^{17}$. Once casting had been concluded, the ring was removed from the centrifugal machine, and after attaining ambient temperature, the test specimen was unmolded and cleaned using airborne-particle abrasion with aluminum oxide $(50 \mu \mathrm{m})$ for 15 seconds to remove investment residues.

\subsection{Analysis of the castings}

The castability of the alloy was determined by the number of segments of the polyester screen completely filled by the alloy, as a percentage of the wax pattern. For this purpose, the castings were evaluated with the aid of a loupe TL-1106 (TekToyo, Curitiba, PR, Brazil), at 40x magnification.

The surface roughness was evaluated using a SJ-201 roughness meter (Mitutoyo ${ }^{\circledR}$ - Tokyo, Japan) with a $1.25 \mathrm{~mm}$ cut-off, at two distinct times: before and after polishing with fine and extra-fine abrasive rubber points (220 and 320 grit respectively) mounted in a polishing machine (7000 rpm/min, Knebel Produtos Dentários Ltda.,
Porto Alegre, RS, Brazil), for 5 minutes. After obtaining the data, they were submitted to statistical analysis (1-ANOVA, Tukey, $\mathrm{p}<0.05)$.

\section{Results and Discussion}

\subsection{Castability}

Castability is the ability of a molten alloy to completely fill a mold space. Poor castability may result in incomplete cast crown margins ${ }^{18}$. The results demonstrated that the Heat Shock investment had the worst performance with regard to this property, with statistically significant difference $(\mathrm{p}<0.05)$ in comparison with the other investments, which had a similar performance among them $(\mathrm{p}>0.05)$ (Figure 1). Furthermore, this investment presented a large spread of castability values, promoting a high standard-deviation of the sample. This indicated that the investment was not capable of providing uniform results, as the other studied materials.

Various factors influence the castability of a metal, such as alloy composition $^{19}$, investment type $\mathrm{e}^{11,18}$, sprue design ${ }^{20-22}$, casting temperature $^{19}$, type of casting machine ${ }^{23}$, surface tension of the alloy, and the direction of force during casting ${ }^{18}$. In this study, centrifugation may have influenced the castability test. It was possible to standardize parameters such as the thermal cycle applied to the material, final mold temperature $\left(950{ }^{\circ} \mathrm{C}\right)$, and number of centrifuge turns (4). However, one difficulty inherent to the process was to determine the ideal length of time to operate the centrifuge, in order to allow the gases generated inside the mold during heat processing when the nylon net and wax was burned, to escape completely ${ }^{17}$; the ideal time

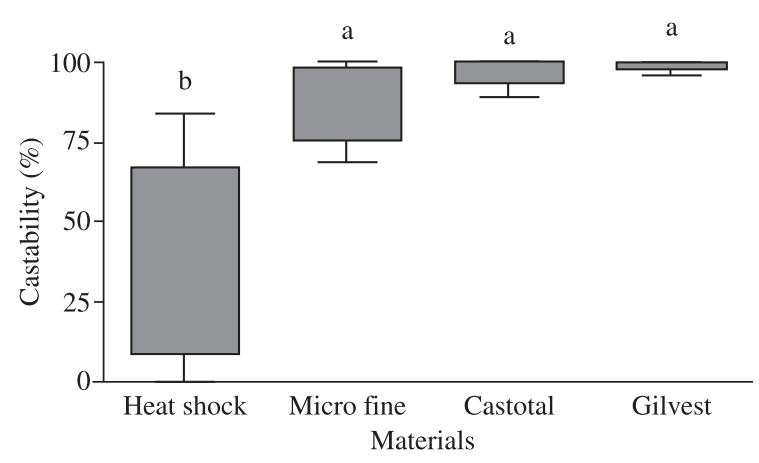

Figure 1. Graphic representation of castability of the tested investments. Different letters indicate statistically significant differences $(\mathrm{p}<0.05)$

Table 1. Materials used in the study.

\begin{tabular}{|c|c|c|c|}
\hline Investment & Composition & Average granulometry $(\mu \mathrm{m})$ & Manufacturer \\
\hline HeatShock & $\begin{array}{l}\text { Powder: Monoammonium Phosphate, Magnesium } \\
\text { Oxide, Silicone Dioxide and Titanium Dioxide } \\
\text { and Fluidizer }\end{array}$ & 33.08 & Polidental, Cotia, SP, Brazil \\
\hline \multirow[t]{2}{*}{ Micro Fine 1700} & $\begin{array}{l}\text { Liquid: Aqueous Suspension of Colloidal Silica } \\
\text { Powder: Quartz, Feldspathic, Phosphate, } \\
\text { Modifying Agents }\end{array}$ & \multirow[t]{2}{*}{32.04} & \multirow[t]{2}{*}{ Talladium-INC, Valencia, USA } \\
\hline & $\begin{array}{l}\text { Liquid: Ethyl Alcohol, Silicone Dioxide, } \\
\text { Agglutinant }\end{array}$ & & \\
\hline \multirow[t]{2}{*}{ Gilvest HS } & Powder: Quartz, Phosphate, Silicone Dioxide & \multirow[t]{2}{*}{31.92} & \multirow[t]{2}{*}{ BK Giulini, Ludwighafen, Germany } \\
\hline & Liquid: Aqueous Suspension of Colloidal Silica & & \\
\hline \multirow[t]{2}{*}{ Castotal } & $\begin{array}{l}\text { Powder: Monoammonium Phosphate, Magnesium } \\
\text { Oxide, Silicone Dioxide and Titanium Dioxide }\end{array}$ & \multirow[t]{2}{*}{31.45} & \multirow[t]{2}{*}{ Polidental, Cotia, SP, Brazil } \\
\hline & Liquid: Aqueous Suspension of Colloidal Silica & & \\
\hline
\end{tabular}


can be determined only by experience. Investments with more rugged powder, such as Heat Shock ${ }^{\circledR}$ (average granulometry 33.08) would facilitate the escape of gases. However, the difficulty of standardizing the force applied by centrifuge may have led to discrepancies in the results. The same happened with the other investments; although they presented smaller particle size, their particle distribution was more uniform, which allowed better escape of gases, leading to complete filling of the mold $^{24}$.

\subsection{Surface roughness}

Due to the hardness of base metal alloys, special equipment is required for cleaning and smoothing the restoration after casting, which considerably limits these procedures in dental offices. Furthermore, machining has routinely been delegated to commercial laboratories, which may lack standardized direct-flame casting equipment, thus producing frameworks with porous and rough surfaces ${ }^{25}$.

The surface smoothness of cast denture frameworks is of great importance in preventing the retention of pathogenic microorganisms; avoiding the increase in the incidence of oral disease ${ }^{26,27}$ and the acceleration of biocorrosion ${ }^{28}$. Greater metal surface roughness requires additional finishing and polishing procedure ${ }^{29}$, increasing the time necessary to complete these procedures, which add to the costs of a cast prosthesis. Furthermore, less initial roughness prevents possible weakening of the structure ${ }^{30,31}$.

Before (Figure 2) and after (Figure 3) polishing, the behavior of the tested materials was similar. In both analyses, Heat Shock ${ }^{\circledR}$ and Castotal surface roughness values were statistically similar ( $p>0.05)$, differing statistically from the other investments $(p<0.05)$, which presented higher surface roughness.

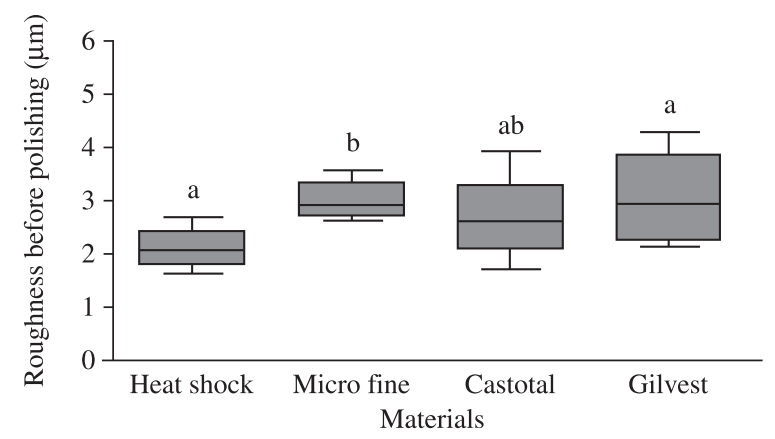

Figure 2. Graphic representation of surface roughness of tested investments before polishing. Different letters indicate statistically significant differences $(\mathrm{p}<0.05)$.

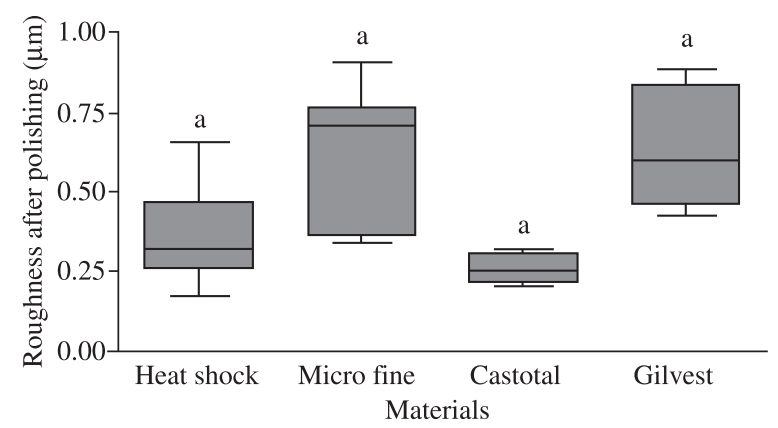

Figure 3. Graphic representation of surface roughness of tested investments after polishing. Same letters indicate no statistically significant differences $(\mathrm{p}>0.05)$.
The characteristic the Heat Shock ${ }^{\circledR}$ and Castotal investments have in common is their composition (Table 1). As regards granulometry, however, they differ: Heat Shock ${ }^{\circledR}$ presents rougher particles, whereas Castotal ${ }^{\circledR}$ has finer particles. The finer the particles of an investment, the smaller will be the surface irregularities of a casting ${ }^{29,32-35}$. Therefore, it was not possible to completely accept the tested hypothesis.

In the same way as with castability, there are other factors that interfere in the surface roughness, such as, the oxygen/acetylene flame used for alloy fusion. Acetylene-oxygen flame casting may cause overheating of the alloy; moreover, use of the oxidizing zone of the flame at lower temperatures, and an oxygen rich environment increase oxidation and can result in increased surface roughness ${ }^{29}$.

When analyzing the results obtained in this study, the initial hypothesis presented must be only partially accepted; that is, the granulometry of the investment used in the casting process of metal alloys has an influence on the castability. Nevertheless, other procedures that constitute the casting process interfere more directly in surface roughness.

\section{Conclusions}

Considering the results obtained, it could be concluded that:

- Heat Shock ${ }^{\circledR}$ investment presented the worst castability results with statistically significant difference $(\mathrm{p}<0.05)$ between it and other investments;

- Before and after polishing Heat Shock ${ }^{\circledR}$ and Castotal ${ }^{\circledR}$ investments presented similar results ( $\mathrm{p}>0.05)$, both with statistically significant difference $(\mathrm{p}<0.05)$ between them and Gilvest and Micro Fine; and

- The granulometry of the investments has a direct influence on the castability of castings, but not on the surface roughness.

\section{References}

1. Winkler S, Morris HF. Changes in mechanical properties and microstructure following heat treatment of a nickel-chromium base alloy. The Journal of Prosthetic Dentistry. 1984; 52(6):821-827.

2. Morris HF, Manz M, Stoffer W, Weir D. Casting alloys: the materials and clinical effects. Advances in Dental Research. 1992; 6(1):28-31.

3. Papazoglou E, Brantley WA, Johnston WM, Carr AB. Effects of dental laboratory processing variables and in vitro testing medium on the porcelain adherence of high-palladium casting alloys. The Journal of Prosthetic Dentistry. 1998; 79(5):514-519.

4. Papazoglou E, Brantley WA. Porcelain adherence vs force to failure for palladium-gallium alloys: a critique of metal-ceramic bond testing. Dental Materials. 1998; 14(2):112-119.

5. Youdelis WV, Youdelis RA. Silver-copper-germanium alloys. Jornal of the Canadian Dental Association. 1981; 47(2):101-106.

6. Tjan AHL, Logan GI, Baum L. Marginal accuracy of complete crowns made from alternative casting alloys. The Journal of Prosthetic Dentistry. 1991; 66(2):157-164.

7. Chern Lin JH, Chen YF, Ju CP. Effect of nickel addition on microstructure and properties of Ti-Co-Ni alloys. Biomaterials. 1995; 16(18):1401-1407.

8. Bezzon OL, Ribeiro RF, Rollo JMDA, Crosara S. Castability and resistance of ceramometal bonding in $\mathrm{Ni}-\mathrm{Cr}$ and $\mathrm{Ni}-\mathrm{Be}$ alloys. The Journal of Prosthetic Dentistry. 2001; 85(3):299-304.

9. Presswood RG. The castability of alloys for small casting. The Journal of Prosthetic Dentistry. 1983; 50(1):36-39.

10. Barreto MT, Goldberg AJ, Nitkin DA, Mumford G. Effect of investment on casting high-fusing alloys. The Journal of Prosthetic Dentistry. 1980; 44(5):504-507.

11. Mori T, Jean-Louis M, Yabugami M, Togaya T. The effect of investment type on the fit of cast titanium crowns. Australian Dental Journal. 1994; 39(6):348-352. 
12. Johnson A, Winstanley RB. The evaluation of factors affecting the castability of metal ceramic alloys: investment combinations. International Journal of Prosthodontic. 1996; 9(1):74-78.

13. Fragoso WS, Henriques GEP, Contreras EFR, Mesquita MF. The influence of mold temperature on the fit of cast crowns with commercially pure titanium. Brazilian Oral Research. 2005; 19(2):139-143.

14. Jang KS, Youn SJ, Kim YS. Comparison of castability and surface roughness of commercially pure titanium and cobalt-chromium denture frameworks. The Journal of Prosthetic Dentistry. 2001; 86(1):93-98.

15. Bedi A, Michalakis KX, Hirayama H, Stark PC. The effect of different investment techniques on the surface roughness and irregularities of gold palladium alloy castings. The Journal of Prosthetic Dentistry. 2008; 99(4):282-286.

16. Ohno H, Nakano S, Miyakawa K, Watanabe, Shiokawa N. Effect of phase transformations of silica and calcium sulfates on the compressive strength of gypsum-bonded investments at high temperatures. Journal of Dental Research. 1982; 61(9):1077-1082.

17. Takahashi J, Zhang JZ, Okazaki M. Effect of casting methods on castability of pure titanium. Dental Materials Journal. 1993; 12(2):245-252.

18. Shimizu H, Habu T, Takada Y, Watanabe K, Okuno O, Okabe T. Mold filling of titanium alloys in two different wedge-shaped molds. Biomaterials. 2002; 23(11):2275-2281.

19. Bezzon OL, De Mattos MG, Ribeiro RF, Rollo JM. Effect of beryllium on the castability and resistance of ceramometal bonds in nickel-chromium alloys. The Journal of Prosthetic Dentistry. 1998; 80(5):570-574.

20. Chai TI, Stein RS. Porosity and accuracy of multiple-unit titanium castings. The Journal of Prosthetic Dentistry. 1995; 73:534-541.

21. Chan DC, Blackman R, Kaiser DA, Chung K. The effect of sprue design on the marginal accuracy of titanium castings. Journal of Oral Rehabilitation. 1998; 25(6):424-429.

22. Leal MB, Paulino SM, Pagnano VO, Bezzon OL. Influence of investment type and sprue number on the casting accuracy of titanium crown margins. The Journal of Prosthetic Dentistry. 2006; 95(1):42-49.

23. Bessing $\mathrm{C}$, Bergman $\mathrm{M}$. The castability of unalloyed titanium in three different casting machines. Swedish Dental Journal. 1992; 16(3): 109-113.
24. Lacy AM, Mora A, Boonsiri I. Incidence of bubbles on samples cast in a phosphate-bonded investment. The Journal of Prosthetic Dentistry. 1985; 54(3):367-369.

25. Taylor TD, Matthews AC, Aquilino SA, Logan NS. Prosthodontic survey. Part I: Removable prosthodontic laboratory survey. The Journal of Prosthetic Dentistry. 1984; 52(4):598-601.

26. Bollen CM, Lambrechts P, Quirynen M. Comparison of surface roughness of oral hard materials to the threshold surface roughness for bacterial plaque retention: a review of the literature. Dental Materials. 1997; 13(4):258-269.

27. Sen D, Goller G, Issever H. The effect of two polishing pastes on the surface roughness of bis-acryl composite and methacrylate-based resins. The Journal of Prosthetic Dentistry. 2002; 88(5):527-532.

28. Mori T, Togaya T, Jean-Louis M, Yabugami M. Titanium for removable dentures. I. Laboratory procedures. Journal of Oral Rehabilitation. 1997; 24(5):338-341.

29. Anusavice KJ. Phillip's Science of Dental Materials. 11 ed. Philadelphia: Saunders; 1996. p. 275.

30. Sato Y. Clinical methods for adjusting retention force of cast clasps. The Journal of Prosthetic Dentistry. 1999; 82(5):557-561.

31. Gapido CG, Kobayashi H, Miyakawa O, Kohno S. Fatigue resistance of cast occlusal rests using $\mathrm{Co}-\mathrm{Cr}$ and $\mathrm{Ag}-\mathrm{Pd}-\mathrm{Cu}-\mathrm{Au}$ alloys. The Journal of Prosthetic Dentistry. 2003; 90(3):261-269.

32. Carter TJ, Kidd JN. The precision casting of cobalt-chromium alloy. Part I: the influence of casting variables on dimensions and finish. Brazilian Dental Journal. 1965; 118(9):383-390.

33. Ogura H, Rapts NC, Asgar K. Inner surface roughness of complete cast crowns made by centrifugal casting machines. The Journal of Prosthetic Dentistry. 1981; 45(5):529-535.

34. Pinto LR, Bonfante G, Lopes JFS. Evaluation of cast metallic posts reproduction according to its quantity and position inside the casting ring. Journal of Applied Oral Science. 2005; 13(1):62-66.

35. Takahashi J, Kitahara K, Kubo F. Phosphate-bonded $\mathrm{ZrSiO}_{4}$ investments added with $\mathrm{ZrC}$ and $\mathrm{ZrN}$ for casting titanium. Dental Materials Journal. 2004; 23(3):314-320. 